\title{
Heterogeneous Catalysis by Flame-Made Nanoparticles
}

\author{
Wendelin J. Stark ${ }^{\mathrm{a}}, \mathrm{b}$, Sotiris E. Pratsinis ${ }^{\mathrm{a} \star}$, and Alfons Baiker ${ }^{\mathrm{b} \star}$
}

\begin{abstract}
In search of highly active nanoparticles for catalytic applications, flame aerosol technology turns out to be a promising method for its capacity to consistently produce highly pure nanoparticles. Starting with the production of simple oxides such as silica and titania in the forties, flame aerosol technology now facilitates production of nanoparticles in megaton quantities. Fundamental research on particle formation in the gas phase and the influence of process parameters and reactor design on final product properties have advanced the field to a stage where multicomponent materials can be produced. Flame production of vanadia/titania catalysts for NOx removal from exhaust gases by selective reduction by ammonia affords enhanced activity at low temperature when compared to corresponding materials prepared by wet-chemical methods. Furthermore, flame synthesis of titania/silica yields catalysts for the epoxidation of olefins with high accessibility of the active titanium sites and improved selectivity. Spectroscopic studies revealed that the same active sites as in the wet-phase derived catalysts are produced by flame synthesis but at a higher content. The high temperature during the preparation favors the formation of well-defined species on a hydrophobic surface. The flame synthesis of heterogeneous catalysts is brought from laboratory scale to pilot scale production at up to $500 \mathrm{~g} / \mathrm{h}$ to make the novel materials suitable for industrial performance tests.
\end{abstract}

Keywords: Catalyst $\cdot$ Epoxidation $\cdot$ Flame $\cdot$ Nanoparticle $\cdot$ NO removal

\section{Introduction}

In industrial chemistry, catalysts do most of the work. In economic terms, they add an estimated $\$ 2.4$ trillion of value worldwide to raw chemical ingredients as scores of industries transform them into petroleum products, synthetic rubber and plastics, food products, chemicals, and pharmaceuticals, or as they control vehicle and industry emissions [1]. Making good catalysts,

${ }^{*}$ Correspondence: Prof. S. E. Pratsinis

aparticle Technology Laboratory

Department of Mechanical and Process Engineering ETH Zentrum, ML F 26

Sonneggstrasse 3

$\mathrm{CH}-8092$ Zürich

Tel.: + 4116323180

Fax: + 4116321595

E-Mail: pratsinis@ptl.mavt.ethz.ch

www.ptl.ethz.ch/staff/pratsinis

${ }^{*}$ Correspondence: Prof. A. Baiker

bLaboratory of Technical Chemistry

ETH Hönggerberg

$\mathrm{CH}-8093$ Zürich

Tel.: +411632 3153

Fax: +4116321163

E-Mail: baiker@tech.chem.ethz.ch

www.baiker.ethz.ch/ however, is a tricky business. Up to now, mostly wet-phase techniques are used in manufacturing catalysts. Incipient wetness impregnation, sol-gel, coprecipitation and grafting, to name but a few, are batch processes and often involve large amounts of solvents. After-treatments, such as filtration, drying and activation by calcining the fresh materials are cost intensive. Alternatives to produce the catalyst directly in one step would therefore be of great use.

With the advent of the nano-wave in science [2], catalyst research has received a strong boost. A series of new methods to produce nanoparticles emerged in the last few years. High-temperature gas-phase synthesis of inorganic nanoparticles offers a choice of complex mixed oxides in industrial quantities. Large scale commodities such as carbon black for tire and rubber reinforcement and titania for white pigments and catalysts are produced today at up to several Mt annually [3]. Aerosol-made zinc oxide is used as an activator of rubber vulcanization, or as a pigment or pharmaceutical additive. Fumed silica is applied as a rheological additive, catalyst support or in the fabrication of optical fibers for telecom- munications. Flame reactors have been developed rather evolutionary, mostly in the second half of the 20th century with little input from particle science and engineering. In fact, the industrial production was running for years before fundamental research on particle formation in flames started in the laboratories of Cabot, DuPont, Degussa, Columbia, Asahi, and others. Today, elaborate models of particle formation in the gas phase allow quantitative description of the effect of process parameters on particle size and morphology [4]. Simplified models are interfaced with computational fluid dynamics to study reactors by Degussa and other industries [5]. They provide an indispensable tool to study the fundamental processes determining particle growth and characteristics in academia [6][7].

Here, we would like to show how flame-made materials exhibit high catalytic performance. As several of these new opportunities arise, the production of complex mixed oxides may shift from wet to mainly dry preparation methods, providing the chemical engineer with a wealth of new materials for catalysis. 


\section{Gas-phase Synthesis of Catalysts}

With a better understanding of the fundamentals of particle formation in flames, the preparation of oxides in the flame can be extended away from the classical, simple oxides of silica, alumina and titania to more complex products. Ulrich suggested the use of flame aerosol technology for the manufacture of catalysts in 1984 [8] as Formenti et al. had shown the photocatalytic potential of flame-made $\mathrm{TiO}_{2}$ [9]. Degussa early on capitalized on the production of simple catalysts such as the titania P25 as a photocatalyst. Miquel et al. prepared vanadia/titania in a counterflow diffusion flame but did not measure any catalytic performance [10]. Moser et al. did some early investigations into the use of hot-wall reactors for the aerosol synthesis of catalysts and found in- teresting silver metal dispersion on alumina [11], high surface area vanadium phosphorous oxide (VPO) [12] and reported on a perovskite for methane oxidation [13]. The activity of the aerosol-made VPO was much higher than wet-phase made VPO but the selectivity for maleic anhydride formation was very low [12]. This motivated us to attempt the synthesis of vanadia/titania DeNO ${ }_{x}$ catalysts in a methane-oxygen coflow diffusion flame [14].

\subsection{DeNOx Catalysts}

In a flame aerosol unit, metal organic precursors, such as alkoxides, $\beta$-ketodionates, halogenes, carbonyls and cyclopentadienyl derivatives are fed through a liquid mass flow controller into an evaporator ( Fig. 1). As saturated carrier gas is brought into a flame, it is converted into the corre- sponding oxides or oxide-supported metal. Nanoparticles can be collected on filters or, in pilot-scale setups, baghouse filter units depending on the production rate. By choosing the burner design, the enthalpy delivery and the metal concentration in the flame, a large variety of products is accessible: In a typical microreactor with a burner diameter of $1 \mathrm{~cm}$, titania powder with specific surface area of 23 to $120 \mathrm{~m}^{2} / \mathrm{g}$ is accessible at a powder production rate of $4 \mathrm{~g} / \mathrm{h}$ [14]. Using a larger pilot scale burner (diameter $2 \mathrm{~cm}$ ), titania and vanadia/titania with 15 to $100 \mathrm{~m}^{2} / \mathrm{g}$ can be produced at up to $200 \mathrm{~g} / \mathrm{h}$, making materials available for large-scale testing [15]. As-prepared $10 \mathrm{wt} \%$ vanadia on titania is highly active for NO removal from exhaust gases. Fig. 2 gives the performance of a flame-made and a wet-phase made [16] DeNOx catalyst.
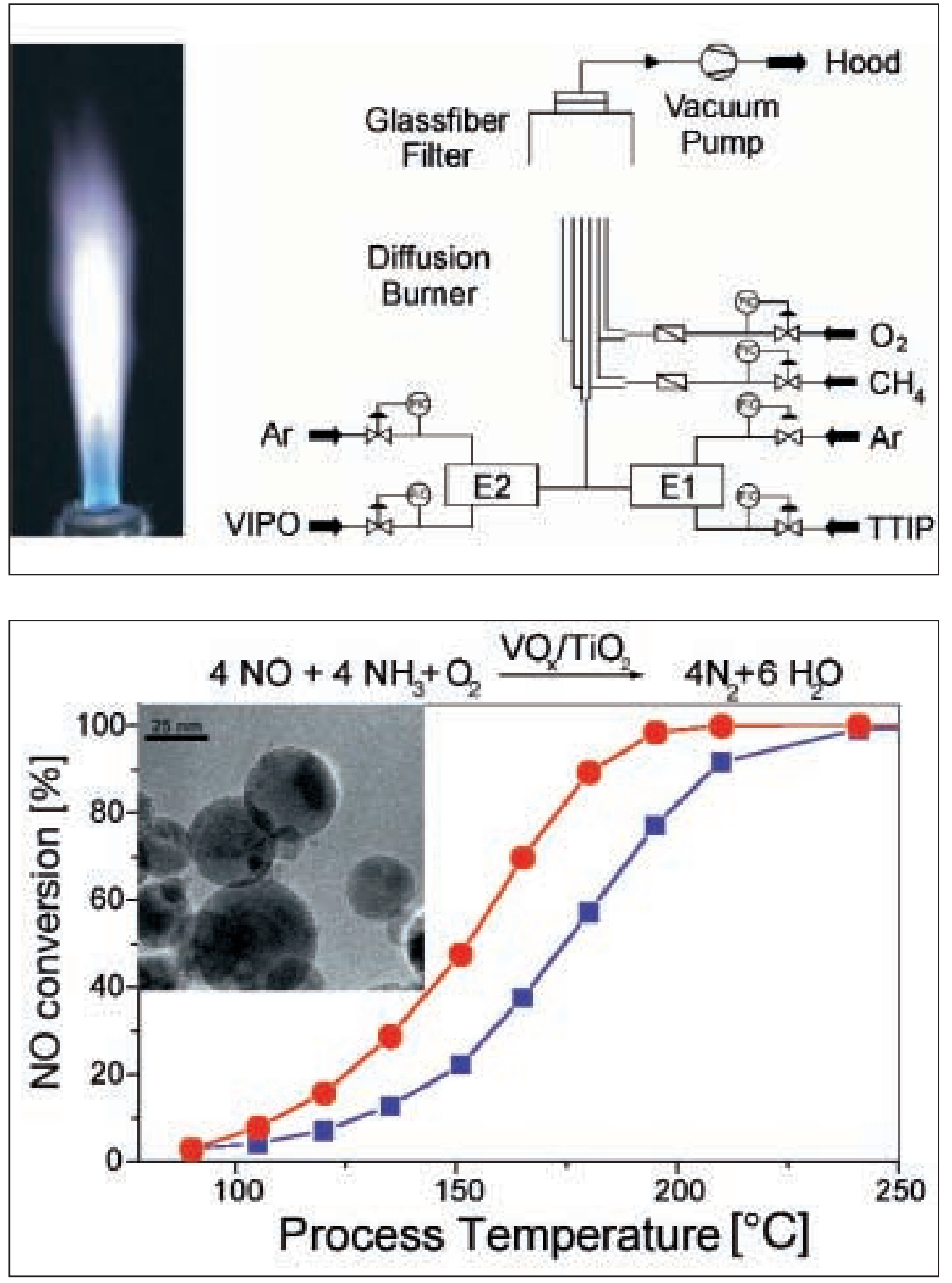

Fig. 1. In flame aerosol synthesis, metal-containing volatile precursors such as vanadiumand titanium-isopropoxide (VIPO, TTIP) are fed through liquid mass flow controllers into an evaporator where they are mixed with a carrier gas. The gaseous mixture is brought into a flame, where chemical reaction leads to the formation of oxides. The product nanoparticles nucleate, condense and grow further by collision, coalescence and surface reaction. Adapted from [14].

Fig. 2. Catalytic performance of flame-made (circles) and wet-phase made (squares) vanadia/titania for the removal of NO from an exhaust stream. The NO is selectively reduced by ammonia, thus forming nitrogen and water. The flame-made material shows improved low temperature activity compared to a corresponding catalyst prepared by grafting [16]. The inlet shows a high resolution electron microscopy image of the catalyst made of spherical, vanadia-coated titania nanoparticles. Adapted from [2]. 
The low temperature activity of the flamemade sample exceeds significantly that of the conventionally prepared catalyst, leading to better low temperature NO removal. Vanadia is a highly volatile oxide and only condenses onto the newly formed titania downstream of the flame, leading to a smooth coating. High preparation temperature favors a dehydrated titania surface and the formation of vanadia oligomers, the most active vanadia species in DeNOx catalysts [17].

\subsection{Epoxidation Catalysts}

Titania/silica is one of the most active catalytic materials for the selective epoxidation of olefins and allyl alcohols [18]. The most prominent example, TS-1, a titania silicalite, contains $\mathrm{Ti}$ in a molecular sieve-like superstructure. It is used industrially for propene-oxide synthesis from propene and tert.-butyl hydroperoxide [19]. Its high selectivity is attributed to a high content of non-hydrated tetrahedral $\mathrm{Ti}$ species. The Ti acts as a redox-inert Lewis acid, where activation of the peroxide bond results in the epoxidation of the coordinat- ing olefin. Brønsted-acid Ti sites and the formation of hydrates block the active site and lead to peroxide loss, olefin oligomerization and low selectivity. Unfortunately, the narrow channel structure of the excellent TS-1 catalyst prohibits its use for bigger reactants. A series of alternative preparation methods were proposed to avoid this limitation. Grafting Ti-containing precursors onto a silica surface or preparing the titania/silica directly by sol-gel methods leads to catalysts with good activity [20]. The low temperature and the fact that hydrolysis water is present during the preparation result in the formation of highcoordinated $\mathrm{Ti}$ sites which easily hydrate. Consequently, the selectivity of such materials is limited if they are not subjected to a special pretreatment (drying) prior to reaction.

Feeding titanium tetraisopropoxide (TTIP) and hexamethyldisiloxane (HMD$\mathrm{SO}$ ) into a methane-oxygen flame results in the formation of heavily agglomerated silica nanoparticles (Fig. 3) with Ti confined to the surface of silica [21]. These catalysts show significantly improved selectivity (above 90\%) for the demanding epoxidation of 2-cyclohexenol by tert.-butylhydroperoxide compared to aerogel- or grafted catalysts (65 to $80 \%$ ) [21]. The formation of the active Ti-O-Si bonds can be confirmed by FTIR spectroscopy and UVVIS spectroscopy corroborating the absence of titania microclusters. No crystalline titania phases are formed and Ti-species are finely dispersed on the silica surface [21]. Using X-ray absorption near edge fine structure spectroscopy (XANES), the tetrahedral structure of the high-temperature Ti/silica could be confirmed (Fig. 4). Comparison of the flame-made samples to the TS-1 silicalite shows a very similar signal. In-situ hydration and dehydration experiments underline the high hydrophobicity of the flame-made oxide. In contrast, corresponding aerogels show strong hydration and the presence of higher coordinated $\mathrm{Ti}$ sites [22]. Production of Ti/silica in a larger pilot-scale burner leads to catalysts with the same activity and selectivity for production rates up to $500 \mathrm{~g} / \mathrm{h}$. Catalysts samples are now subject to industrial scale testing [23].
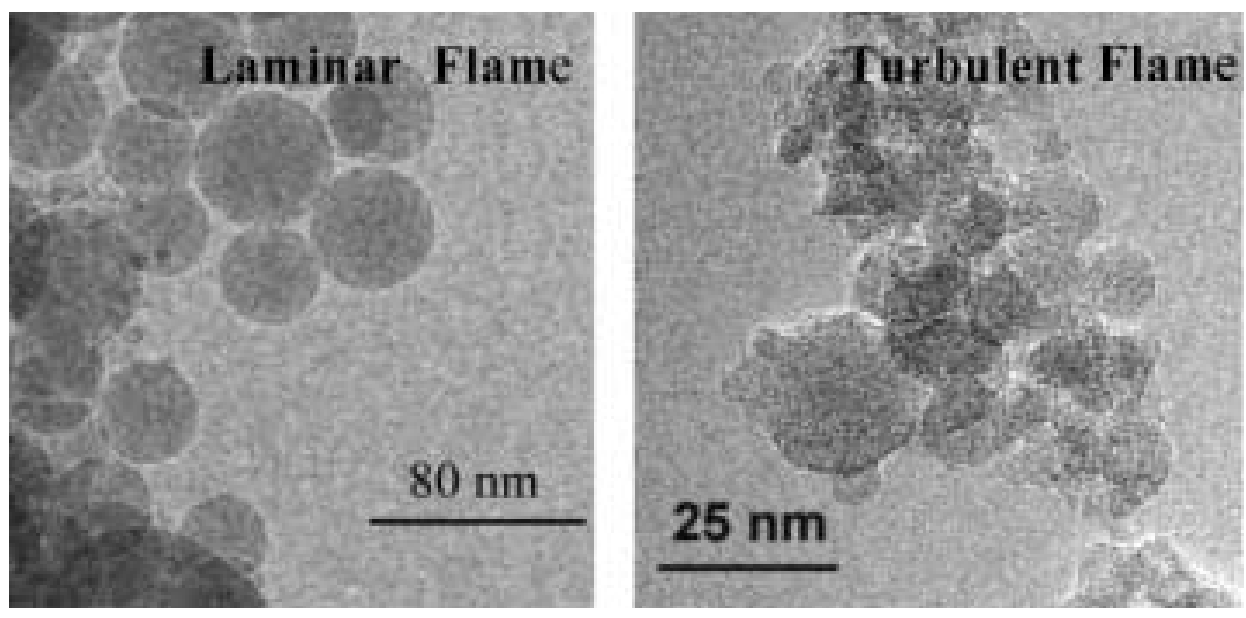

Fig. 3. Titania/silica nanoparticles, prepared in a laminar, rather long, hot flame (left) and in a short, oxygen rich and highly turbulent flame (right). The long high-temperature residence time in the laminar flame leads to prolonged particle growth and sintering, resulting in large, spherical particles. Highly aggregated nanoparticles of much smaller size are formed in the shorter flame. These high specific surface area nanoparticles are especially attractive for catalysis. Adapted from [21].

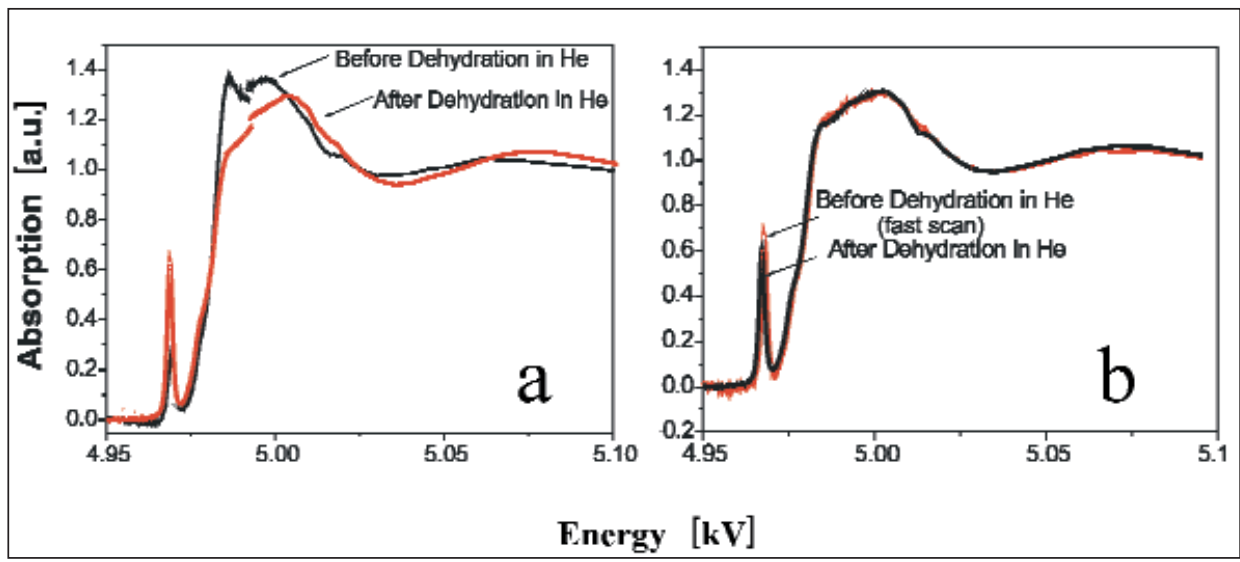

Fig. 4. X-ray absorption near edge spectroscopy (XANES) of (a) titania/silica aerogels and (b) flame-made Ti/silica reveals the fundamental difference of dry-prepared catalysts. The aerogels are strongly hydrated and contain a mixture of 4,5 , and 6 -fold coordinated $\mathrm{Ti}$ leading to Brønsted acidity and reduced selectivity (65\%) [22]. The flame-made catalysts show no hydration of the Ti sites and only contain tetrahedral $\mathrm{Ti}$ resulting in much improved selectivity (above 90\%) for the epoxidation of 2-cyclohexenol by tert.-butylhydroperoxide in toluene. Adapted from [22]. 


\subsection{High-purity Catalysts - The Key to High Selectivity}

Flame aerosol synthesis is a no-movingparts, continuous process where the product has very few and short interactions with equipment. This allows for the production of high purity oxides even under standard laboratory conditions. Typical flame-made silica contains less than $3 \mathrm{ppm}$ of transition metal impurities, something that led to its wide applications in lightguides for telecommunications [24]. This impurity level can only be reached with cumbersome and expensive precautions by wet-phase preparation [25]. The latter generally leads to metal leaking from stirrers, reaction vessels or entrain impurities during its multiple process steps leading to occasional product inconsistency. Since flame aerosol synthesis uses readily available volatile precursors and the particle formation fully proceeds in the gas phase, few opportunities for contamination are given.

Controlled doping of chromium, manganese, iron and cobalt into Ti/silica and comparing their selectivity for the above epoxidation revealed that as little as $40 \mathrm{ppm}$ of transition metals lowered drastically the selectivity of the reaction [25]. As wetphase made materials contain typically around $50 \mathrm{ppm}$ transition metal impurities, at least, some of the by-product formation could be suppressed by using purer materials to start with.

\subsection{Large-scale Production of Catalysts}

Scaling up the production from laboratory scale to an application level often entails considerable difficulty. Batch processes can be cumbersome to scale-up and in the case of sol-gel technology, critical issues comprehend various details of the process making it a challenging task to increase production rate. Particle formation in the gas phase is an extremely fast process, initiated by the formation of nuclei of the oxide. Then primary particles grow by condensation of gaseous oxide onto the surface, or by collision with other particles, followed by sintering [26]. These processes are active throughout the hot zone of a flame. If ambient air entrainment cools the gases below a certain level, particle collisions only result in aggregates. Locally, the particle condensation is a fast process, principally diffusion controlled, since the gases readily reach a highly supersaturated state in the flame. Taking mixed oxide synthesis from the laboratory to an application scale therefore deals with balancing high temperature residence time against oxide concentration in the flame. We have shown this for vanadia/titania and titania/silica; both very different systems since in the latter the two constituents are condensing extremely fast. In contrast, for the DeNOx vanadia/titania catalysts, highly volatile vanadia condenses on prior formed titania. The pilot-scale production of these two distinctly different examples of mixed oxides suggests that the production of other mixed oxide materials is also feasible [15][23].

The high preparation temperature encountered during flame synthesis generally results in morphologically uniform (surface tension), thermodynamically relaxed products. In the case of non-mixing solids such as titania and silica, the Ti ions are all situated on the surface in the same tetrahedral configuration [22]. Differences in volatility may be directly used to produce smooth coatings of an active component on a surface $\left(\mathrm{VO}_{\mathrm{x}} / \mathrm{TiO}_{2}\right.$ for DeNOx applications) [14]. Metals can be readily deposited onto oxides using a gas-phase process, since the metals generally poorly wet oxide surfaces [7]. This leads to the desired morphology of highly accessible metal nanoparticles on a carrier oxide surface (Fig. 5).

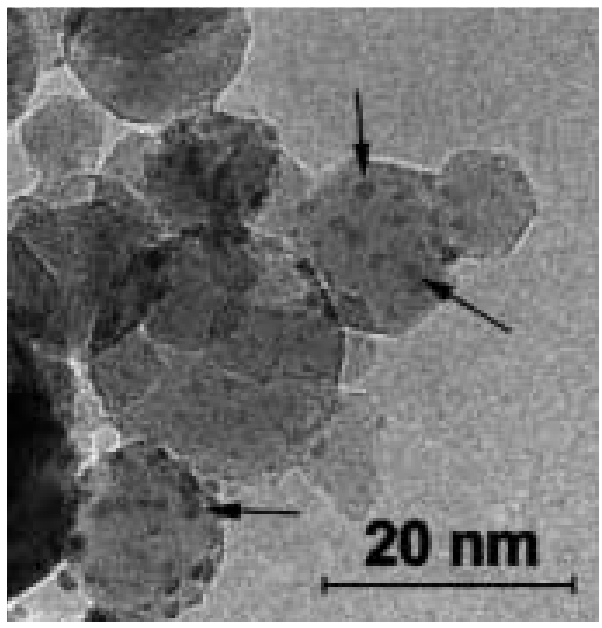

\subsection{Flame Spray Synthesis}

Gas phase synthesis of catalysts may be extended to non-volatile precursors with flame spray pyrolysis. Here, a liquid is sprayed to fine droplets and directly fed into a flame. Rapid evaporation and combustion spread the precursor compounds in the hot gas environment. Particle formation now proceeds as in the case of flame aerosol synthesis [27]. Spray flame synthesis is very attractive for the production of oxides of the earth- and rare-earth metals, where volatile precursors are cost intensive. This opens the gas phase synthesis route to ceramic superconductors [28][29], dielectrics such as barium titanate [30], battery materials such as strontium and nickel manganates [31] and magnesium aluminum spinels [32][33]. Or, in the case of ceria, nanoparticles of excellent temperature stability can be prepared [34]. As in the case of flame aerosol synthesis, flame spray pyrolysis can be brought to higher production rate $(1.1 \mathrm{~kg} / \mathrm{h},[35])$. Multicomponent liquids tend to undergo phase separation or selectively precipitate part of the reactant, therefore producing ill-defined products. In some cases, this may even be favorable, as was shown for the production of hollow particles of bismuth oxide [36] or in the preparation of alumina-supported Pt catalysts for the enantioselective hydrogenation of ethyl-pyruvate [37].

\section{Outlook}

Flame synthesis of heterogeneous catalysts produces mixed oxide nanoparticles with high activity for $\mathrm{NO}_{\mathrm{x}}$ removal and improved selectivity for the epoxidation of olefins compared to conventionally prepared oxides. These dry, gas-phase made powders exhibit a very low degree of hydratization, homogeneous morphology and

Fig. 5. Spherical titania particles spot-coated with uniform, extremely small $\mathrm{Pt}$ particles (1-6 nm) made by flame spray synthesis of platinum and titanium containing precursors. The difference in volatility and surface tension between titania and platinum determine the product morphology. Here, titania particles are formed in the early stages of the flame, while Pt condenses onto the titania surface later on. These materials exhibit high activity for $\mathrm{SO}_{2}$ oxidation [7]. Courtesy of R. Strobel, $\mathrm{ETHZ}$. 
well-defined chemical species. In the case of vanadia/titania, the flame synthesis favors the formation of highly active $\mathrm{VO}_{\mathrm{x}}$ oligomers while in titania/silica, tetrahedral Ti sites form preferentially. The continuous pilot scale production of mixed oxides at up to $500 \mathrm{~g} / \mathrm{h}$ illustrates the potential of flame aerosol synthesis for manufacturing complex products at an application level [23]. With flame aerosol synthesis as a rather inexpensive route for large-scale production of nanoparticles, the production of mixed oxides may increasingly shift from wet to dry preparation methods. This may offer new avenues to catalysts with enhanced performance and even to new products.

\section{Acknowledgements}

Financial support by the Swiss National Science Foundation, ETH (Gesuch No. 19/01-1) and the Swiss Commission for Technology and Innovation, (Top Nano 21, 5352.1) is kindly acknowledged.

Received: July 25, 2002

[1] L.B. Schilling, National Institute of Standards and Technology NIST 2001, www.atp.nist.gov/www/press/catalyst.htm.

[2] W.J. Stark, S.E. Pratsinis, Powder Technology 2002, 126, 103

[3] 'Chemical Economics Handbook', SRI International, Merlo Park, 2001.

[4] Y. Xiong, S.E. Pratsinis, J. Aerosol Sci. 1993, 24, 283.

[5] A. Schild, A. Gutsch, H. Muehlenweg, S.E. Pratsinis, J. Nanoparticle Res. 1999, 1,305 .

[6] T. Johannessen, S.E. Pratsinis, H. Livbjerg, Chem. Eng. Sci. 2000, 55, 177.

[7] T. Johannessen, S. Koutsopoulos, J. Catal. 2002, 205, 404.

[8] G.D. Ulrich, Chem. Eng. News 1984, 62 (Aug. 6), 22.

[9] M. Formenti, F. Juillet, P. Meriaudeau, S.J. Teichner, P. Vergnon, J. Colloid Interface Sci. 1972, 39, 79.

[10] F.M. Miquel, C.H. Hung, J.M. Katz, J. Mater. Res. 1993, 8, 2404.

[11] W.R. Moser, J.A. Knapton, C.C. Koslowski, J.R. Rozak, R.H. Vezis, Catal. Today 1994, 21, 157.

[12] W.R. Moser, Catalytic Selective Oxidation, Ed. S.T. Oyama, Hightower, ACS Symposium Series, 1993, 523, 244.

[13] W.R. Moser, J.D. Lennhoff, Chem. Eng. Comm. 1989, 83, 241.

[14] W.J. Stark, K. Wegner, S.E. Pratsinis, A. Baiker, J. Catal. 2001, 197, 182.

[15] W.J. Stark, A. Baiker, S.E. Pratsinis, Particle and Particle Systems Characterization 2002, in press.

[16] A. Baiker, P. Dollenmeier, M. Glinski, US Patent 4789533, 1988, assigned to Lonza AG.; A. Baiker, P. Dollenmeier, M. Glinski, A. Reller, Appl. Catal. 1987, 35, 351.
[17] A. Baiker, B. Handy, J. Nickl, M Schraml-Marth, A. Wokaun, Catal. Lett. 1992, 14, 89.

[18] M. Dusi, T. Mallat, A. Baiker, Catal. RevSci. Eng. 2000, 42(1\&2), 213.

[19] R. Kumar, G.C.G. Pais, B. Pandey, P. Kumar, J. Chem. Soc. Chem. Commun. 1995, 1315.

[20] R. Hutter, T. Mallat, D. Dutoit, A. Baiker, Top. Catal. 1996, 3, 421.

[21] W.J. Stark, S.E. Pratsinis, A. Baiker, J. Catal. 2001, 203, 516.

[22] J.D. Grunwaldt, C. Beck, W.J. Stark, A Hagen, A. Baiker, Phys. Chem. Chem. Phys. 2002, 4, 3514.

[23] W.J. Stark, H.K. Kammler, R. Strobel, D. Günther, A. Baiker, S.E. Pratsinis, Ind. Eng. Chem. Res. 2002, 41, 4921.

[24] J.B. MacChesney, R.E. Jaeger, D.A. Pinnow, F.W. Ostermayer, T.C. Rich, L.G. Van Uitert, Appl. Phys. Lett. 1973, 23, 340.

[25] W.J. Stark, R. Strobel, D. Gunther, A. Baiker, S.E. Pratsinis, J. Mater. Chem. 2002, accepted.

[26] S.E. Pratsinis, Prog. Energy Combust. Sci. 1998, 24, 197.

[27] L. Mädler, H.K. Kammler, R. Mueller, S.E. Pratsinis, J. Aerosol Science 2002, 33, 369.

[28] M.R. Zachariah, S. Huzarewicz, Combustion and Flame 1991, 87, 100.

[29] G. Feldmann-Schlobohm, B. Mueller, M. Kuntz, D. Raulin, R. Riddle, U.S. Patent 5.814.585, 1998.

[30] J.H. Brewster, T.T. Kodas, AIChE Journal 1997, 43, 2665.

[31] R. Kriegel, J. Topfer, N. Preuss, S. Grimm, J. Boer, J. Mater. Sci. Lett. 1994, 13, 1111.

[32] C.R. Bickmore, K.F. Waldner, D.R. Treadwell, R.M. Laine, J. Am. Ceram. Soc. 1996, 79, 1419.

[33] R.M. Laine, R. Baranwal, T. Hinklin, D. Treadwell, A. Sutorik, C. Bickmore, K. Waldner, S.S. Neo, Key. Eng. Mat. 1999, $159,17$.

[34] L. Maedler, W.J. Stark, S.E. Pratsinis, $J$. Mater. Res. 2002, 17, 1356.

[35] R. Mueller, L. Mädler, S.E. Pratsinis, submitted for publication.

[36] L. Mädler, S.E. Pratsinis, J. Am. Ceram. Soc. 2002, in press.

[37] R. Strobel, W.J. Stark, L. Mädler, S.E. Pratsinis, A. Baiker, J. Catal. 2002, in press. 